Nobel prizes-have dovetailed neatly into the universities of which they are often a part.

Observing that medical research is largely conducted by or within universities, the annual report is doing no more than note one unexceptionable reason why the M.R.C.'s links must always be of the closest with those institutions. But the clinician is aware too of the enormous benefits to the treatment of patients that the pharmaceutical industry has brought about in the last 20 years. The medicinal revolution, unfashionable though it is to say so in some circles, owes much of its success to the discovery, isolation, or purification of drugs and other remedies through research undertaken in drug firms. Though the molecular roulette for quick profit has often been criticized, the barely mentionable though not unknown practice of facile but pointless investigation for quick prestige in academic circles usually gets by. In this field of judgement - the choice of worthwhile research-the M.R.C. has exerted a thoroughly healthy influence and been conspicuously successful. Selecting the right projects and backing these financially must always be a bit of a gamble, but the Council takes care to shorten the odds against it by having as its members and advisers many leaders in their field, most of them in university appointments.

At present the M.R.C. is giving priority in its support to four special problems of our time. They are mental disorder, arterial disorder (in particular coronary thrombosis), population control, and drug dependence (including tobacco smoking). It considers also that certain specialties need encouragement "if research is to be developed"-namely, psychiatry, clinical neurology, obstetrics and gynaecology, dermatology, dentistry, virology, and mycology. Anyone with enthusiasm for his subject could make out a good case for having it added to the list, so many are the promising lines of research that seem to lie open in medicine today, but one useful addition might be resuscitation and the treatment of injuries, for accidents and attempted suicide now constitute a substantial proportion of hospital work.

The latest report departs from custom in that it omits the bulky section giving details of the research supported by the M.R.C. That is to be published as a separate handbook.

\section{Handicapped Children}

The face of our social services has undergone increasing scrutiny in recent years: and the more it has been scrutinized the more warts and other blemishes are discovered-the iniquities of Ely, ${ }^{1}$ the accusations of Sans Everything, ${ }^{2}$ and the revelations of Put Away. ${ }^{3}$

Now comes Living with Handicap, ${ }^{4}$ a report published by the National Bureau for Co-operation in Child Care. It is based on data compiled by a multidisciplinary working party. Fifty-eight professional and voluntary organizations and some individuals submitted written evidence; ten county and county borough councils gave accounts of their respective facilities.

1 Committee of Enquiry into Allegations of Ill-treatment of Patients and other Irregularities at the Ely Hospital, Cardiff, Report, Cmnd. 3975. London, H.M.S.O., 1969.

2 Robb, B., Sans Everything: A Case to Answer. London, Nelson, 1967.

3 Morris, P., Put Away: A Sociological Study of Institutions for the Mentally Retarded. London, Routledge and Kegan Paul, 1969.

4 Living with Handicap, ed. E. Younghusband, D. Birchall, R. Davie, M. L. Kellmer Pringle. National Bureau for Cooperation in Child Care, Adam House, 1 Fitzroy Square, London W'.1., 50s. 1970.

5 Committee on Local Authority and Allied Personal Services, Report, Cmnd. 3703. London, H.M.S.O., 1968.
Finally, an indication of "consumer reactions" was obtained from letters written by 412 parents in response to invitations in the national press. This is obviously a biased sample and represents the views of the more articulate, intelligent, and socially conscious section of the community. Nevertheless, despite their statistical invalidity the replies are poignant, and extracts from them serve as texts on which each chapter of the report is based. One father wrote that there was "more autism among the local authorities than he had ever found in his daughter." This sad comment is echoed in many other letters and highlights the feeling of hopelessness engendered by the rigid departmentalization of the available services, with the inevitable buck-passing. Such despair reinforces the recommendation in the Seebohm report, ${ }^{5}$ wholeheartedly endorsed by the working party, that social and family needs can be effectively met only through a compact social services department.

The report is concerned with the problems and indeed agonies of parents and families trying to cope with handicapped children. The range of handicaps is enormous. Physically they may vary from the cosmetic disadvantages of congenital malformations of the external ear to those tragic, living monuments to man's pharmacological conceit, the thalidomide children. They include varieties of sensory deprivation from partial to complete. There are the degrees of intellectual impairment; and last but by no means least there is the full range of psychological troubles, from emotional disturbances, through behaviour disorders, to autism and childhood psychosis. For good measure throw in the permutations and combinations of multiple handicaps and the problems, individually and collectively, stretch out to infinity.

The report makes it clear that mental handicap is far less easily tolerated by the public at large than physical handicap. As a sort of corollary, the worst fear of parents of mentally handicapped children seems to be that, for whatever reason, they will finally be admitted to a subnormality hospital. Such is the reputation of these institutions, not entirely deserved, but the result no doubt of the indiscriminate mud-slinging to which they have been lately subjected.

Any assessment of the size of the need to be met in numerical terms is bound to fall wide of the mark for the simple reason that one of Parkinson's laws applies: the provision of any kind of special facility will immediately uncover more children needing it than was originally estimated. None-the-less Michael Power and Jean Packman's approximation is quoted. They calculated that in 1966 there were 21,000 children with physical handicaps and 24,000 with mental handicaps living in boarding schools and hospitals, plus a further 115,600 children who were receiving help from their homes-a gigantic total.

The ultimate plea of the working party is that each child should receive help, including formal education, according to his individual needs, and that this should be given with the minimum of separation from his normal fellows and the minimum disturbance of normal family life. It would be churlish to maintain that nothing is being done to this end. In truth, a great deal is achieved by both professional and voluntary organizations; but the ideal of a tailor-made service to suit each handicapped child will always be unrealistic. As living standards rise, however, so should the quality of care provided for the handicapped. The new Secretary of State must soon decide what his priorities are to be-and he has already shown sympathy for the mentally handicapped (see Parliament, p. 232). This report makes a powerful additional claim for all children who need any form of special care. 